Article

\title{
PV-Powered Charging Station for Electric Vehicles: Power Management with Integrated V2G
}

\author{
Dian Wang, Manuela Sechilariu *(D) and Fabrice Locment
}

Alliance Sorbonne University, Université de Technologie de Compiègne, AVENUES, 60203 Compiègne, France; dian.wang@utc.fr (D.W.); fabrice.locment@utc.fr (F.L.)

* Correspondence: manuela.sechilariu@utc.fr; Tel.: +33-(0)3-4423-7317

Received: 11 August 2020; Accepted: 16 September 2020; Published: 17 September 2020

check for updates

Featured Application: This article presents a photovoltaic (PV)-powered charging station for electric vehicles with power management that integrates vehicle-to-grid (V2G). Based on a DC microgrid integrating PV sources, the charging station is controlled by a searching peak and valley algorithm. Following the description and the validation simulation, a PV-powered charging station for electric vehicles represents a high potential for application because it can be easily implemented as a project pilot in urban areas.

\begin{abstract}
The increase in the number of electric vehicles (EVs) has led to an increase in power demand from the public grid; hence, a photovoltaic based charging station for an electric vehicle (EV) can participate to solve some peak power problems. On the other hand, vehicle-to-grid technology is designed and applied to provide ancillary services to the grid during the peak periods, considering the duality of EV battery "load-source". In this paper, a dynamic searching peak and valley algorithm, based on energy management, is proposed for an EV charging station to mitigate the impact on the public grid, while reducing the energy cost of the public grid. The proposed searching peak and valley algorithm can determine the optimal charging/discharging start time of $\mathrm{EV}$ in consideration of the initial state of charge, charging modes, arrival time, departure time, and the peak periods. Simulation results demonstrate the proposed searching peak and valley algorithm's effectiveness, which can guarantee the balance of the public grid, whilst meanwhile satisfying the charging demand of EV users, and most importantly, reduce the public grid energy cost.
\end{abstract}

Keywords: electric vehicle; charging station; energy management; searching peak and valley algorithm; power management; microgrid; vehicle-to-grid

\section{Introduction}

Due to the advantages of no noise, low environmental pollution, high efficiency of energy use, and simple structure, electric vehicles (EVs) have received widespread attention [1,2]. With the development and popularization of EVs, large-scale EVs will be connected to the public grid for charging in the future $[3,4]$. The EV distribution in time and space has great randomness and uncertainty [5,6], thus, a large number of random and unmanaged EVs having access to the public grid will inevitably have a serious impact on the public grid: load growth, increased difficulty in public grid operation control, and a large number of power distribution network upgrades $[7,8]$. Therefore, how to coordinately control the energy flow between EVs and the public grid is a key issue.

In order to reduce the peak loads, the paper [9] proposes a real-time dynamic pricing model for EVs charging/discharging service and building energy management. In practice, many EVs are traveling on the road for only $4-5 \%$ of the day, while they are parked for the rest of the time [10]. Research on bidirectional on-board chargers makes electric vehicle (EV) discharge possible [11]. 
EVs can discharge into the public grid during its "peak" periods and can be charged during its "valley" periods to achieve the purpose of peak shaving and valley filling [12]. When EVs need an energy supply, they are connected to the public grid as charging loads; when EVs are idle, i.e., EVs are seen as distributed power sources, EV battery energy can be injected into the public grid. This is the vehicle-to-grid (V2G) operation. Thus, V2G technology makes it possible for EVs to have a mobile battery function [13]. Moreover, compared with common loads, EVs have greater flexibility and dispatchability. When reasonable scheduling strategies for V2G technology are designed, and the charging/discharging behavior of EVs is planned, EV charging costs will be reduced, most importantly, the load curve of the public grid will be improved. The paper [14] proposes a time-based charging group dispatching approach to schedule the charging of numerous EVs, which enables EVs to play an important role in peak shaving and valley filling, meanwhile solving the stability problem of the microgrid system brought by the penetration of renewable energy. EV batteries and related power electronics can be used to mitigate photovoltaic (PV) sources' impact and support the public grid with appropriate control strategies. The paper [15] develops a controllable charge/discharge pattern to optimize the limitation of EV battery capacity and the impacts of PV sources. Most importantly, EVs can provide instant power, which is much faster than starting a standby power source. So, V2G technology enables EVs to act as emergency power sources in the event of a power outage [16,17]. V2G can bring economic benefits to EV users, offset part of the EV costs, promote communication between the public grid and EVs, meanwhile, protect the environment, and solve the shortage of fossil energy. V2G services are important for reducing environmental pollution, mainly referring to the emission of greenhouse gases such as $\mathrm{CO} 2$ [18].

With the continuous development of renewable energy, such as PV sources, more and more renewable energy is being integrated into the power system in large quantities. Considering the intermittency and distribution of PV sources, microgrids are proposed to achieve small-scale renewable energy penetration while reducing the public grid stress $[19,20]$. Surveys show that most EV users can accept the intelligent EV charging station based on a microgrid [21,22]. The paper [23] proposes the model for an EV charging station. However, the above microgrid models and simulations do not consider V2G. Traditional V2G technology mainly refers to EVs directly connected to the public grid for energy exchange. Generally, two types of control exist in systems: centralized control and decentralized control [24]. The former has high construction costs, while the latter has the problem of difficult control. Therefore, the V2G based on a direct current (DC) microgrid control mode is proposed, which makes EVs connect to the public grid through a DC microgrid, moreover, it effectively integrates renewable energy, whilst meanwhile saving the cost of buying electricity from the public grid. V2G based on the microgrid is used for multi-objective optimization coordination between EVs and the public grid to minimize grid load fluctuation, maximize renewable energy utilization, and maximize the benefits for the EV users [25]. The paper [26] proposed a centralized model to co-optimize the transformer loss-of-life with benefits for EV users on charging/discharging management. As an optimal energy cost solution, cyber insurance was introduced to guarantee the best price for charging/discharging, which is effective not only in dealing with cyber risks but also in maximizing revenue for EV users [10]. The paper [27] develops a model predictive control-based approach to address joint EV charging scheduling and power control to minimize both EV charging cost and energy generation cost in meeting both residence and $\mathrm{EV}$ power demands.

A DC microgrid with integrated V2G has also been examined in other papers [28,29]. The paper [28] proposes an optimal day-ahead operation planning procedure that aims to minimize microgrid operation daily costs, according to suitable load demand and source availability forecast without involving MATLAB/SIMULINK modeling. The review paper [29] focuses on the charging system components, architecture, operational modes, and control, including the interaction between the PV sources, public grid, energy storage unit, and power electronics, however, it does not take into account the management of multiple EVs. In addition, V2G was characterized as a comparatively advantageous means of peak load shaving [10]. The paper [24] proposes an optimal logical control 
algorithm based on V2G to reduce the average charging cost of EVs, which is dedicated to the French energy billing system within the peak/base hour's contract. The algorithm can minimize the EV charging cost and maximize energy selling by using daily energy price profiles, considering constraints and disruptions: EV arrival/departure times, and the desired state of charge $\left(\operatorname{soc}_{E V}\right)$ for the next use. However, this algorithm has not yet involved a PV-powered charging station and research in the microgrid field.

In a V2G system, the EV charging station can obtain the optimal charging/discharging start time by reading the EV's arrival time, departure time, initial state of charge namely $S O C_{E V}$ in, and the state of charge limit at the time of departure, namely $S O C_{E V_{-} \text {final_lim. }}$. Based on the above, this paper proposes an $\mathrm{EV}$ charging station management with integrated $\mathrm{V} 2 \mathrm{G}$, in which the optimal charging/discharging start time for EVs can be achieved to perform the purpose of peak and valley filling through a dynamic searching peak and valley algorithm (SPVA). Compared with the power limit of the public grid in the "valley" period, the power limit of the public grid absorbed from the microgrid is larger, while the power limit of the public grid released to the microgrid is smaller during the "peak" period. Therefore, when EVs connect to discharge, the charging station will select a time point near the "peak" periods for EVs; when EVs connect to charge, the charging station will choose a time point far away from the "peak" periods, which can not only relieve the pressure on the public grid but also reduce unnecessary charging costs.

In order to protect the stability of the public grid, the energy injected into the public grid needs to be limited, namely the self-protection mechanism of the public grid. To better ensure the stability of the public grid, the power limit of the power grid is set to different values according to the "peak" periods and "valley" periods.

This paper studies the power management of a PV-powered charging station with integrated V2G from two aspects of energy scheduling and real-time control. The main contributions of this work are:

(1) An EV charging station model combined with V2G based on a DC microgrid is proposed, which consists of four parts: PV sources, a storage system, a public grid connection, and EVs. This model makes use of EV's "load-source" character to bring benefits to users while meeting user needs.

(2) A suitable power management strategy for the EV charging station with integrated V2G is proposed. In the strategy, the priority order for charging EVs is PV sources, the storage system, the public grid. During the "peak" periods of the public grid, the DC microgrid discharges to the public grid, and the discharge priority order is PV sources and then the EVs, considering the discharge cost.

(3) The SPVA is proposed to calculate the optimal charging/discharging start time of EVs to achieve the effect of peak shaving and valley filling, while meeting the charging requirements of EVs, taking into account the EV arrival time, departure time, $S O C_{E V_{-} \text {in, }}$ and $S O C_{E V_{-} \text {final_lim. }}$. Most importantly, it reduces the cost of the public grid, which is beneficial to the public grid and EV users.

(4) A reasonable electricity price mechanism is set which provides the possibility for SPVA. In order to protect the stability of the public grid, the charge/discharge power limits are different in accordance with the "peak" periods and "valley" periods of the public grid.

The presented DC microgrid structure with integrated V2G is described in Section 2. Power flow management: grid-to-vehicle (G2V) and V2G algorithm is introduced in Section 3. Simulation results and analyses are presented in Section 4. Conclusions and further works are given in Section 5.

\section{DC Microgrid Structure with Integrated V2G}

The microgrid, which plays an important role in the production of a smart grid, which can produce the integrated operation of multiple power sources and loads, can coordinately control the public grid and can meet users' requirements for power quality, power reliability, and safety. 
A microgrid based on a DC common bus is considered due to its superior current control because there are no negative and zero sequence currents [30]. The design of an EV charging station including V2G is based on DC microgrid. As shown in Figure 1, the DC microgrid is composed of four parts: PV sources, a storage system, a public grid connection, and EVs.

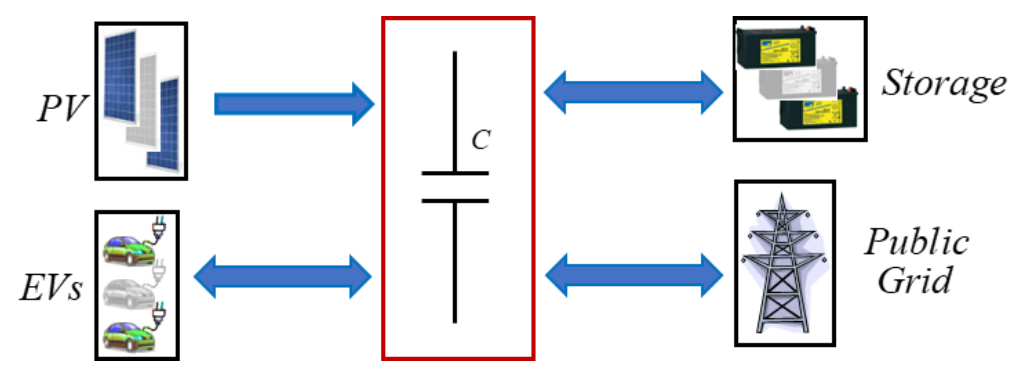

Figure 1. DC microgrid with integrated vehicle-to-grid (V2G). PV: photovoltaic sources, EV: electric vehicles.

DC microgrid power flow is shown in Figure 2: "PV" represents PV sources, "PG" represents the public grid, "S" represents the storage system, "EV" represents EVs. The real-time power priority is shown by the arrow. For example, PV sources firstly support EVs, secondly charge storage, then thirdly inject into the public grid.

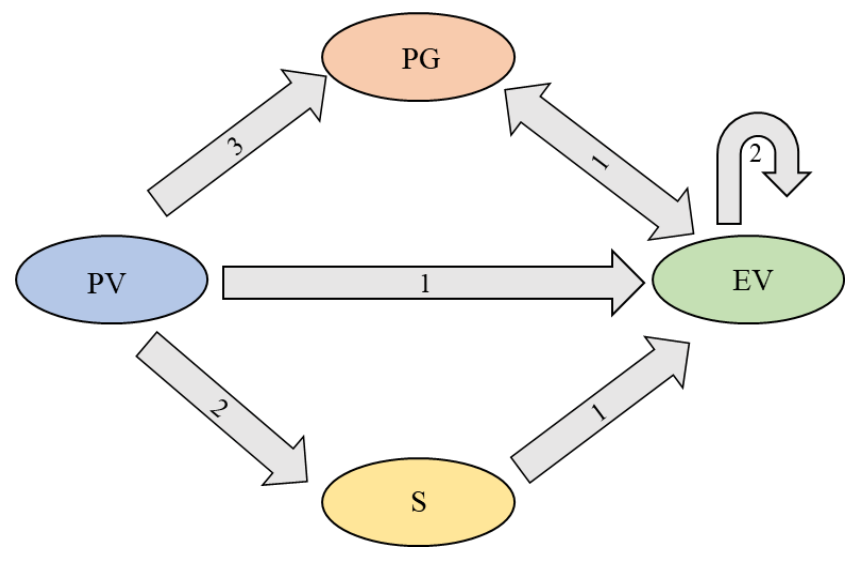

Figure 2. DC microgrid power flow. PG: public grid, S: storage system.

According to the "peak" periods and "valley" periods of the public grid, the energy flow of the DC microgrid can be divided into two cases. During the "valley" periods of the public grid, the electricity produced by PV sources is first used to charge EVs. Storage is the second-ranked energy source for charging EVs; in addition, it is also used to absorb excess energy produced by PV sources. The public grid is the third-ranked energy source for charging EVs, and it can buy excessive energy from PV sources. During the "peak" periods of the public grid, the order of charging EVs is the same as the "valley" periods of the public grid, and the difference is that V2G is achievable during this period. If the energy produced by PV sources is still surplus after being supplied to the EVs, to adjust the peak-valley difference of the public grid, PV sources can inject excess energy into the public grid. Besides, the energy released by EVs can be injected into the public grid. Considering the energy cost, the order of injecting energy into the public grid is PV sources firstly, then EVs batteries.

During the period of V2G, in order to ensure the power balance of the public grid, the power injected into the public grid, namely $p_{\text {inject_G }}$, should be limited. It may be assumed that the maximum power injected into the public grid cannot exceed the estimated PV power under standard test conditions (STC), namely $P_{P V_{-} S T C}$, which is shown in Equation (1), where $p_{P V}$ is PV power that can 
be injected into the public grid, $p_{E V_{-} \text {total }}$ is the power that EVs can output. $c_{P V}$ is the coefficient of PV power, and $c_{E V}$ is the coefficient of the energy that EVs can release.

$$
p_{\text {inject_G }}=P_{P V_{-} S T C}=c_{P V} p_{P V}+c_{E V} p_{E V_{-} \text {total }}, \text { with } c_{P V}, c_{E V} \in[0,1]
$$

\section{Power Flow Management: G2V and V2G Algorithm}

According to users' wishes and the actual situation of EVs batteries, EVs can be divided into two types, only accept to charge, i.e., grid-to-vehicle (G2V), and only accept to discharge, i.e., V2G. The stored energy of the EV battery is $E$, the maximum energy that EVs can discharge is $E_{\text {discharge }}$ and the maximum energy that EVs can be charged is $E_{\text {charge }}$, which can be calculated by Equations (2) and (3), respectively.

$$
\begin{aligned}
& \begin{cases}E_{\text {charge }}=E \cdot\left(S O C_{E V_{-} f i n a l \_l i m}-S O C_{E V_{-} \text {in }}\right) & \text { if } S O C_{E V_{\_} \text {in }}<S O C_{E V_{-} \text {final_lim }} \\
0 & \text { if } S O C_{E V_{-} i n}=S O C_{E V_{-} \text {final_lim }}\end{cases} \\
& \begin{cases}E_{\text {discharge }}=E \cdot\left(S O C_{E V_{-} i n}-S O C_{E V_{-} f i n a l \_l i m}\right) & \text { if } S O C_{E V_{-} i n}>S O C_{E V_{-} \text {final_lim }} \\
0 & \text { if } S O C_{E V_{-} i n}=S O C_{E V_{-} f i n a l \_l i m}\end{cases}
\end{aligned}
$$

This section presents two algorithms for power flow management of G2V and V2G, which are demonstrated within an EV charging station to simultaneously support multiple EVs.

\subsection{Immediate Charge/Discharge Algorithm (ICDA)}

ICDA means that after the EV is successfully connected to the charger, as long as the EV operating power is within the EV power limit, the EV can be charged/discharged immediately, without considering other restrictions. The flow chart of ICDA is shown in Figure 3.

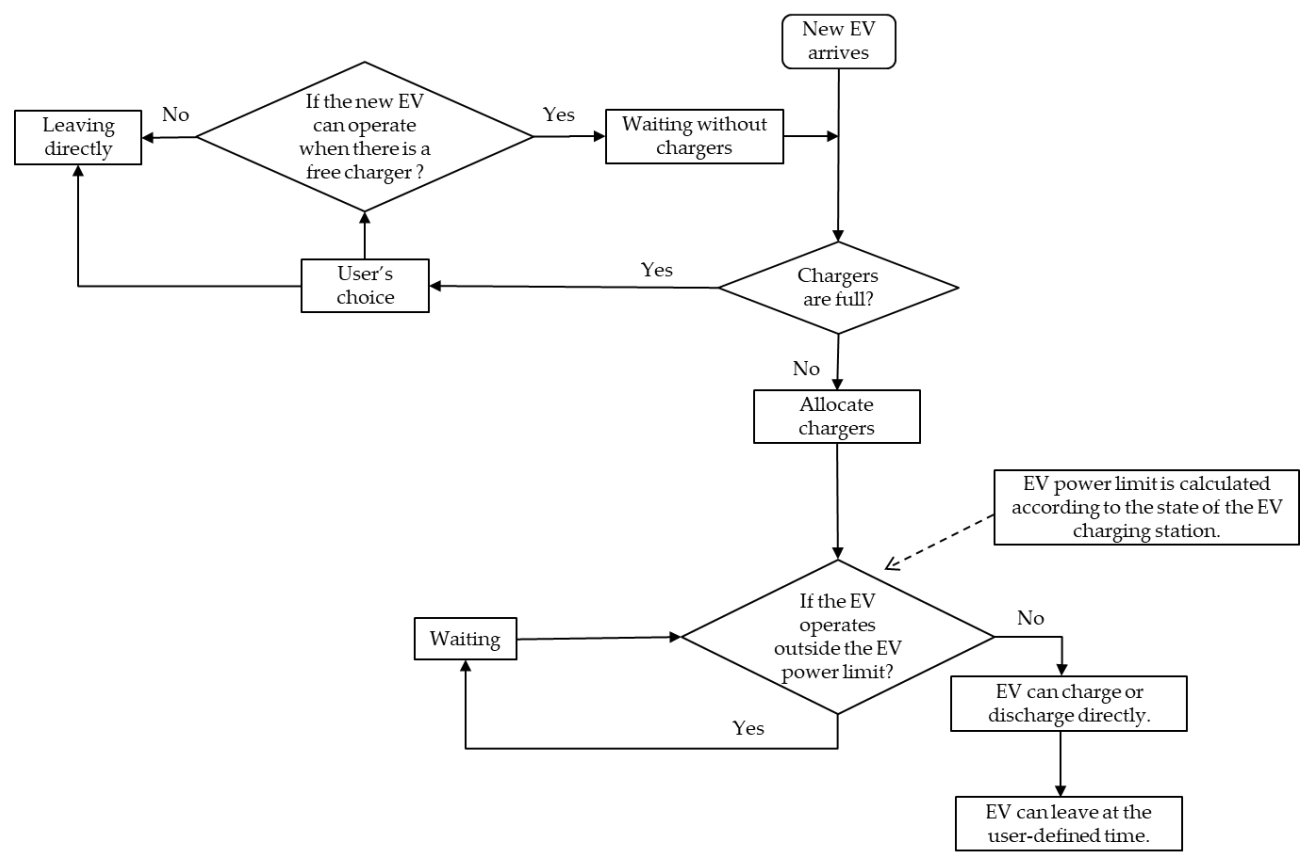

Figure 3. Flow chart of immediate charge/discharge algorithm (ICDA).

When a new EV arrives, if there is a free charger, the charger is directly allocated to the EV. By comparing the EV operating power with the power limit of the EV charging station, it is determined whether the EV enters the waiting state or can be directly charged/discharge until $s o c_{E V_{-} \text {final_lim }}$ is reached, and finally, the EV leaves the EV charging station at the time set by the user. The EV power 
limit is calculated according to the state of the EV charging station. If there are no free chargers when the EV arrives, the EV can choose to leave directly or wait until a free charger appears.

\subsection{Dynamic Searching Peak and Valley Algorithm}

The method to estimate the optimal start operating time is shown in Figure 4. As shown in Figure 4, the EV estimator is the related function of EV information and grid power information. The purpose of SPVA is to estimate the optimal start operating time of EVs by searching the "peak" periods and "valley" periods of the public grid.

The flow chart of SPVA is shown in Figure 5. When a new EV arrives, the EV estimator calculates the optimal operating time of EVs. After the EV is connected to the charger, the EV remains to wait until the optimal operation time appears.

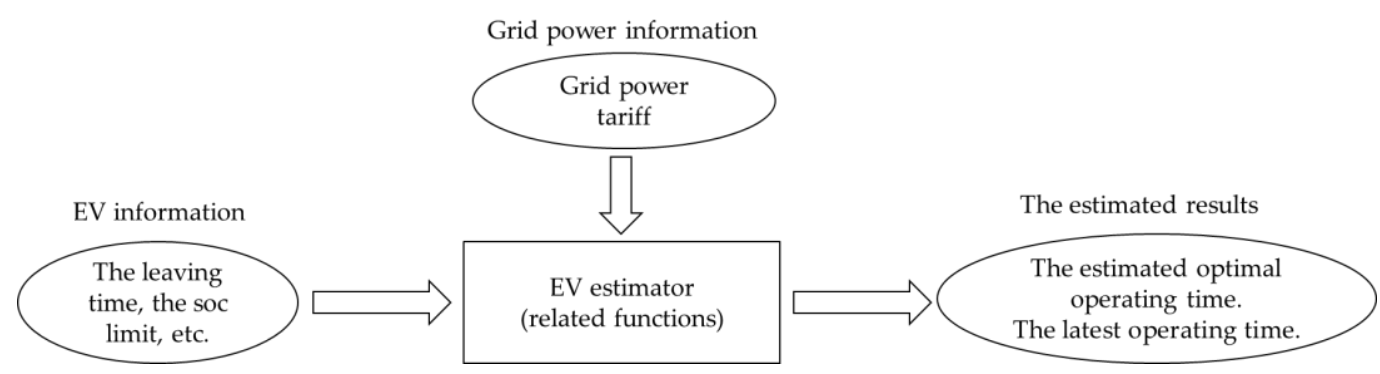

Figure 4. Method to estimate the optimal start operating time.

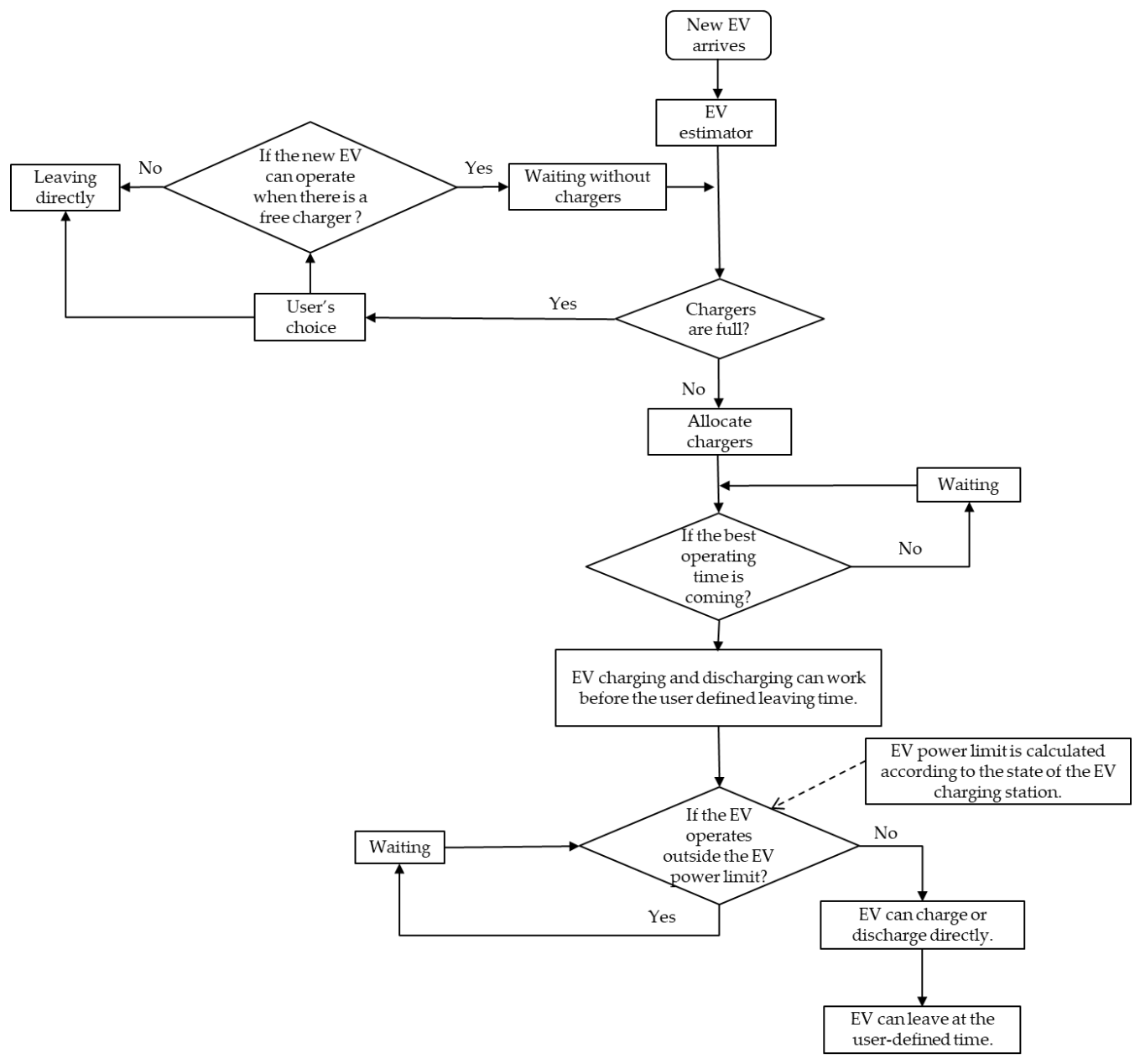

Figure 5. Flow chart of searching peak and valley algorithm (SPVA). 


\section{Simulation Results and Analyses}

In the DC microgrid system, PV sources include $400 \mathrm{PV}$ panels (40 in parallel and 10 in series), and its power under standard conditions is $100 \mathrm{~kW}$ [31]. The storage voltage and capacity are $300 \mathrm{~V}$ and $300 \mathrm{Ah}$, respectively. The public grid is a low-voltage three-phase network with a frequency of $50 \mathrm{~Hz}$. The charging method of lithium-ion batteries in EVs is constant current/constant voltage, while the discharge is constant power. The battery energy of EV is about $24 \mathrm{kWh}$, namely $J_{E V_{-} E R F}$. There are three charging modes in the charging station: fast mode whose maximal charging power is $83 \mathrm{~kW}$, namely $P_{F A S T \_M A X}$; average mode whose maximal charging power is $27 \mathrm{~kW}$, namely $P_{A V E R \_M A X}$; slow mode whose maximal charging power is $7 \mathrm{~kW}$, namely $P_{S L O W \_M A X}$.

\subsection{Simulation Conditions and Assumptions}

In order to ensure the validity of the simulation, it is assumed that all EVs have the same battery characteristics. We can configure different battery characteristics, such as capacity, according to the EV model [32], which will be mentioned in future research. Figure 6 shows the real solar irradiance and PV cell temperature from 8:00 to 22:00 on 28 May 2019, at Compiegne, France.

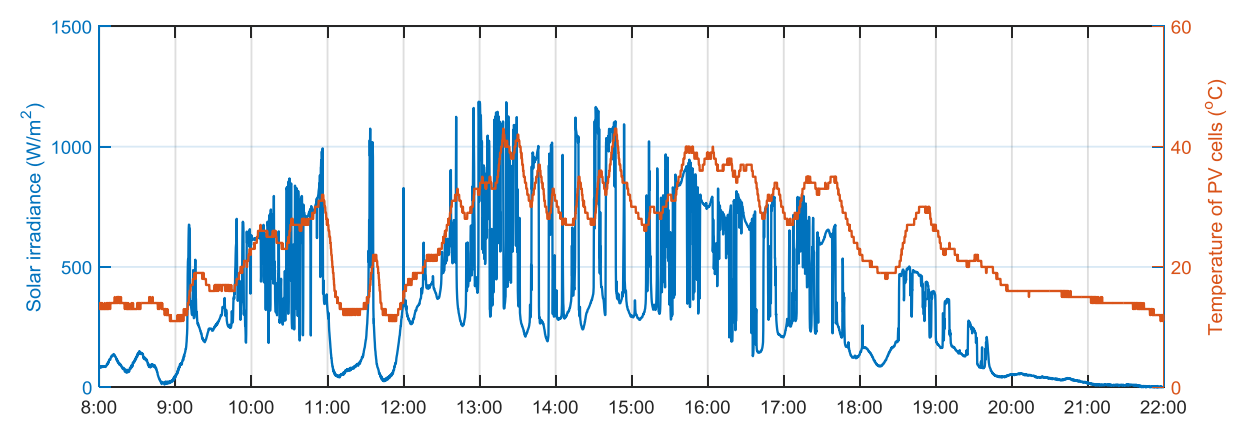

Figure 6. Solar irradiance and PV cell temperature.

In order to highlight the "peak" periods of the public grid, the energy tariff of the public grid from 8:00 to 22:00 is designed as shown in Figure 7. It exists two grid "peak" periods 11:00-13:00 and 18:00-20:00, and the tariff is fixed during the two time-periods. The closer the time point to these two time-periods, the higher the tariff to absorb power from the public grid, which encourages EVs to discharge close to the "peak" periods of the public grid and charge away from the "peak" periods of the public grid.

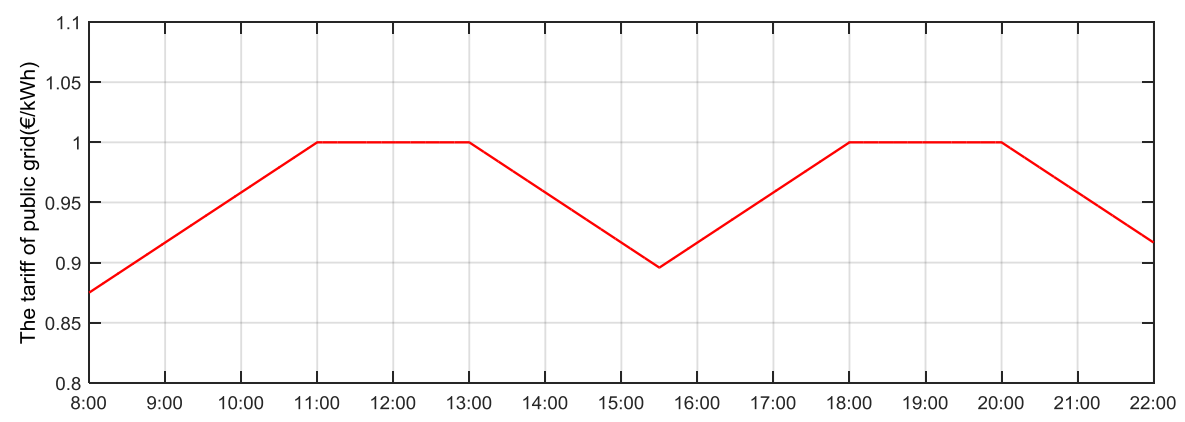

Figure 7. Energy tariff of the public grid.

The simulation parameters of the system are detailed in Table 1 [31], where $P_{D I S}$ is the constant discharge power, which was chosen $89.6 \mathrm{~kW}, I_{S_{-} M A X}$ is the storage current limitation, $S O C_{M I N}$ and $S O C_{M A X}$ are the soc lower limit and the soc upper limit, respectively, $C_{E R F}$ is the capacity of the storage, and $v_{C_{-} R E F}$ is the rated voltage of $\mathrm{DC}$ bus. 
Table 1. Simulation parameters of the system.

\begin{tabular}{cccc}
\hline Parameter & Value & Parameter & Value \\
\hline$P_{F A S T \_M A X}$ & $83 \mathrm{~kW}$ & $I_{S \_M A X}$ & $115 \mathrm{~A}$ \\
$P_{A V E R \_M A X}$ & $27 \mathrm{~kW}$ & $S O C_{M I N}$ & $20 \%$ \\
$P_{S L O W \_M A X}$ & $7 \mathrm{~kW}$ & $S O C_{M A X}$ & $80 \%$ \\
$P_{D I S}$ & $89.6 \mathrm{~kW}$ & $C_{E R F}$ & $300 \mathrm{Ah}$ \\
Number of chargers & 5 & $v_{C \_R E F}$ & $400 \mathrm{~V}$ \\
$J_{E V \_E R F}$ & $24 \mathrm{kWh}$ & $P_{P V \_S T C}$ & $100 \mathrm{~kW}$ \\
\hline
\end{tabular}

The power limits of the point of common coupling of the EV charging station with the public grid are shown in Table 2. Since loads of the public grid are different according to different periods, the power limits are set accordingly to ensure the stability of the public grid. There are two types of power limits: grid injection power limit and grid supply power limit. In the "peak" periods of the public grid, the injection power limit is $100 \mathrm{~kW}$, the supply power limit is $-10 \mathrm{~kW}$, and in other periods, the injection power limit is $50 \mathrm{~kW}$, and the supply power limit is $-50 \mathrm{~kW}$.

Table 2. Power limits of the public grid.

\begin{tabular}{cccccc}
\hline Period & $\mathbf{8 : 0 0 - 1 1 : 0 0}$ & $\mathbf{1 1 : 0 0 - 1 3 : 0 0}$ & $\mathbf{1 3 : 0 0 - 1 8 : 0 0}$ & $\mathbf{1 8 : 0 0 - 2 0 : 0 0}$ & $\mathbf{2 0 : 0 0 - 2 2 : 0 0}$ \\
\hline Grid injection power limit $(\mathrm{kW})$ & 50 & 100 & 50 & 100 & 50 \\
Grid supply power limit $(\mathrm{kW})$ & -50 & -10 & -50 & -10 & -50 \\
\hline
\end{tabular}

The simulation parameters of EVs are shown in Table 3. The three charging modes for EVs, i.e., fast mode, average mode, and slow mode, are considered. When a new EV arrives, the user can choose waiting or departure if there is no free charger. " $\mathrm{CH}^{\prime}$ "represents "charge", "DCH" represents "discharge", "F" represents "fast mode", "A" represents "average mode", "S" represents "slow mode", "W" represents "waiting", and " $\mathrm{D}$ " represents "departure". Ordinal ${ }_{E V}$ represents the ordinal number of EVs.

Table 3. Simulation parameters of EVs. CH: charge, DCH: discharge, F: fast mode, A: average mode, S: slow mode, W: waiting, D: departure.

\begin{tabular}{|c|c|c|c|c|c|c|c|c|}
\hline Ordinal $_{E V}$ & 1st & 2nd & 3 rd & 4th & 5 th & 6th & 7th & 8th \\
\hline$T_{\text {arrive }}(100 s)$ & 17 & 20 & 87 & 198 & 213 & 331 & 336 & 343 \\
\hline$T_{\text {depart }}(100 s)$ & 42 & 75 & 204 & 311 & 222 & 388 & 405 & 400 \\
\hline$S O C_{E V_{-} i n}(\%)$ & 66 & 87 & 47 & 21 & 49 & 37 & 12 & 44 \\
\hline$S O C_{E V}$ final_lim & 11 & 97 & 1 & 78 & 82 & 87 & 9 & 40 \\
\hline Type & $\mathrm{DCH}$ & $\mathrm{CH}(\mathrm{F})$ & $\mathrm{DCH}$ & $\mathrm{CH}(\mathrm{S})$ & $\mathrm{CH}(\mathrm{A})$ & $\mathrm{CH}(\mathrm{A})$ & $\mathrm{DCH}$ & $\mathrm{DCH}$ \\
\hline Choice & W & W & W & $\mathrm{D}$ & $\mathrm{D}$ & W & $\mathrm{D}$ & W \\
\hline Ordinal $_{E V}$ & 9th & 10th & 11th & 12th & 13th & 14th & 15th & 16th \\
\hline$T_{\text {arrive }}(100 s)$ & 356 & 375 & 382 & 398 & 428 & 462 & 471 & 484 \\
\hline$T_{\text {depart }}(100 s)$ & 449 & 464 & 423 & 460 & 431 & 601 & 495 & 499 \\
\hline$S O C_{E V_{-} i n}(\%)$ & 48 & 38 & 41 & 40 & 26 & 37 & 17 & 66 \\
\hline$S O C_{E V}$ final_lim & 26 & 81 & 44 & 92 & 19 & 27 & 65 & 80 \\
\hline Type & $\mathrm{DCH}$ & $\mathrm{CH}(\mathrm{S})$ & $\mathrm{CH}(\mathrm{A})$ & $\mathrm{CH}(\mathrm{A})$ & $\mathrm{DCH}$ & $\mathrm{DCH}$ & $\mathrm{CH}(\mathrm{S})$ & $\mathrm{CH}(\mathrm{F})$ \\
\hline Choice & W & W & $\mathrm{D}$ & $\mathrm{D}$ & W & W & W & $\mathrm{D}$ \\
\hline
\end{tabular}

In this case, in order to reflect the effectiveness of the algorithm, the EV number is randomly given 16, and "Type" and "Choice" are randomly generated by an algorithm. $T_{\text {arrive }}$ represents the time each $\mathrm{EV}$ arrives at the charging station. $T_{\text {depart }}$ represents the time each EV leaves the charging station. $S O C_{E V \_}$in represents the initial $S_{C} C_{E V}, S O C_{E V_{-} \text {final_lim }}$ represents the limit value of $\operatorname{soc}_{E V}$ when the EV departures that set by users. According to the willingness of users, EVs come to charging stations for two purposes: being charged and discharging. 


\subsection{Simulation Results under ICDA}

The first simulation case works under ICDA and the EV can directly be charged/discharge within the EV power limit. As shown in Figure 8, the steady DC bus voltage is $400 \mathrm{~V}$ within the simulation period, which proves that the power management strategy works well to balance the powers under ICDA.

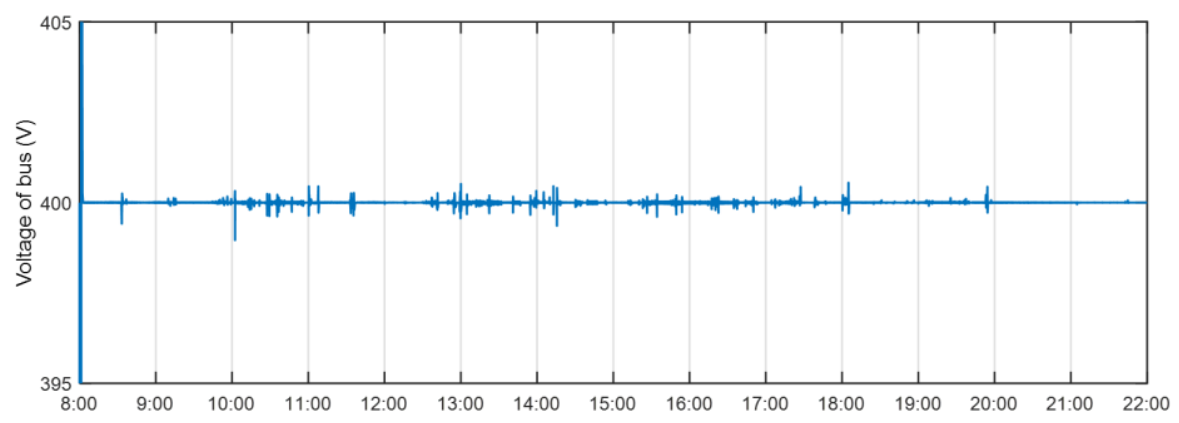

Figure 8. DC bus voltage evolution under ICDA.

Figure 9 shows the storage soc and distribution coefficient $k$ under ICDA. The soc of storage is limited between $20 \%$ and $80 \%$ to extend storage life [33]. $k=1$ means only the storage is working and $k=0$ means only the public grid is working. $0<k<1$ means the storage and the public grid are working simultaneously.

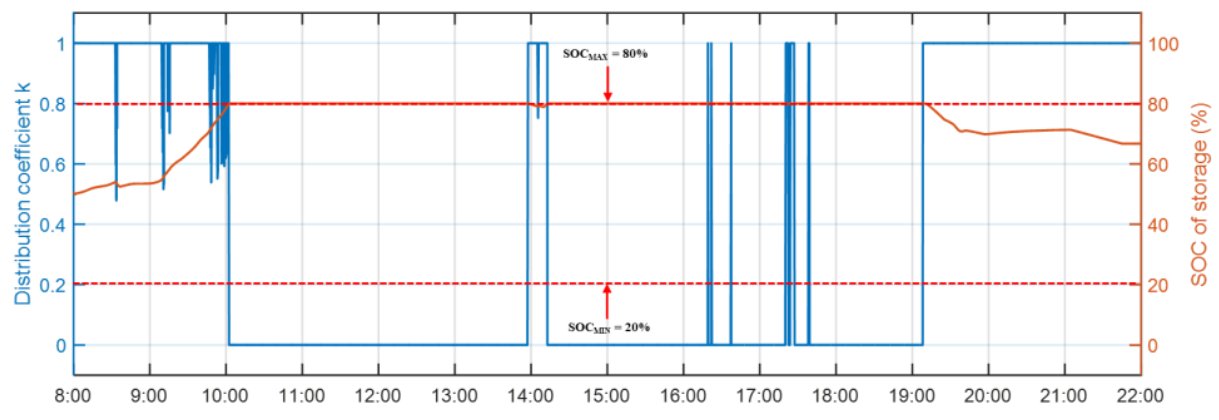

Figure 9. Storage $s o c$ and distribution coefficient $K$ under ICDA.

Storage current evolution under ICDA is shown in Figure 10. The storage current is between $-115 \mathrm{~A}$ and $115 \mathrm{~A}$ to reduce the damage of the storage. The value $-115 \mathrm{~A}$ is the maximum discharge current of batteries, while the value $115 \mathrm{~A}$ is the maximum current for batteries to be charged. The simulation result shows that the current is successfully limited.

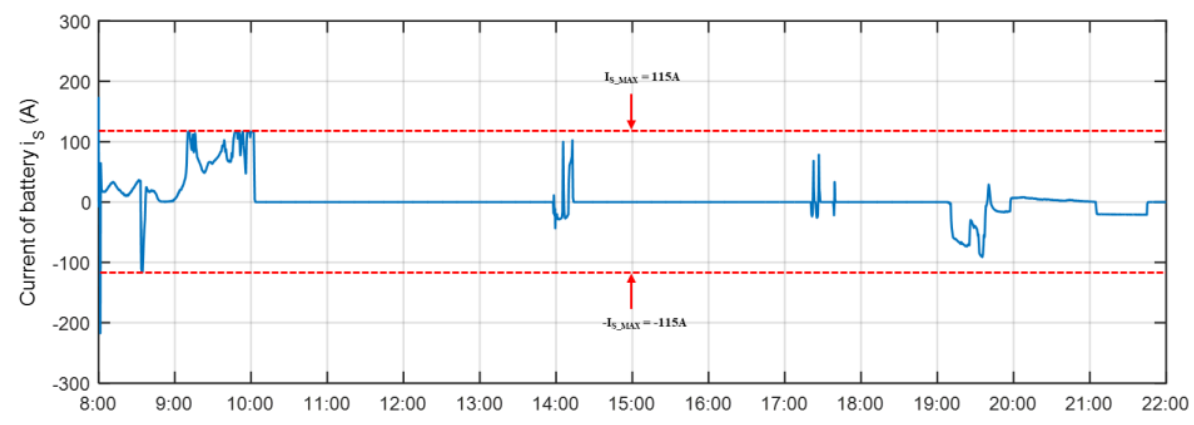

Figure 10. Storage current evolution under ICDA.

The power flow of the DC microgrid under ICDA is shown in Figure 11. PV source can switch freely between PV-constrained production control and PV - maximum power point tracking control [34]. 
The power $p_{E V s}<0$ means that EVs show a total tendency to discharge, $p_{E V s}>0$ means that EVs show a total tendency to be charged. During the "peak" periods of the public grid: 11:00-13:00 and 18:00-20:00, the injection power limit is $100 \mathrm{~kW}$, and the supply power limit is $-10 \mathrm{~kW}$ to prevent the public grid from overloading. During the "valley" periods of the public grid, the injection power limit is $50 \mathrm{~kW}$, and the supply power limit is $-50 \mathrm{~W}$. Setting different power limits according to the "peak" periods and "valley" periods of the public grid is beneficial to improve the stability of the public grid, which also respects the power flow given in Figure 2.

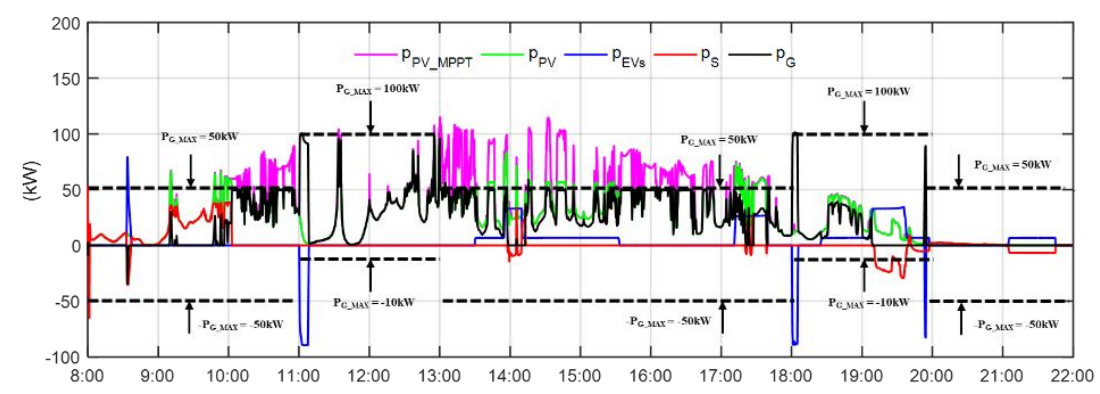

Figure 11. Power flow of DC microgrid under ICDA.

Figure 12 shows the parking periods of EVs. The parking periods of EVs are different according to the willingness of users. From EV_charger_1 to EV_charger_5 represent EVs connected to chargers one to five, respectively, e.g., EV_charger_1 represents the ordinal number and parking periods of the EVs connected to the charger one.

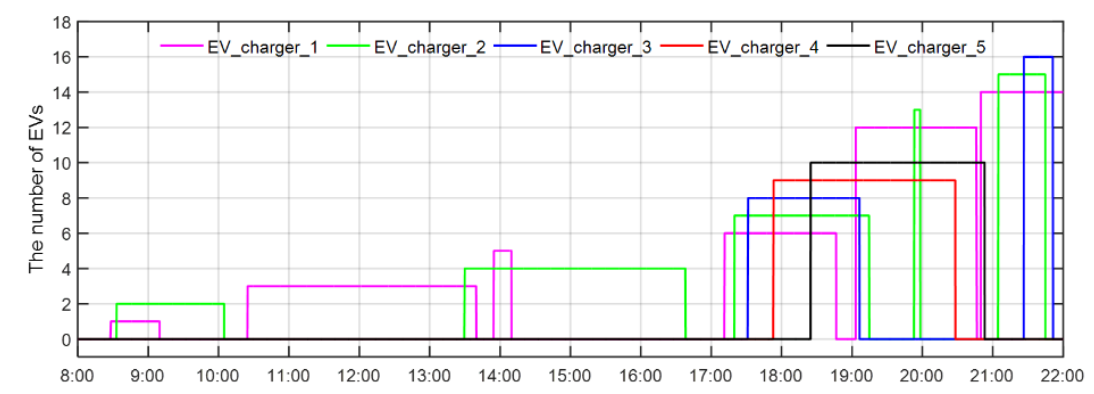

Figure 12. Parking periods of EVs at each charger.

The power evolutions of EVs under ICDA are shown in Figure 13. If the power is positive, it means that the EV is being charged; if it is negative, it means that the EV discharges. Figure 14 shows the $\operatorname{soc}_{E V}$ evolutions under ICDA.

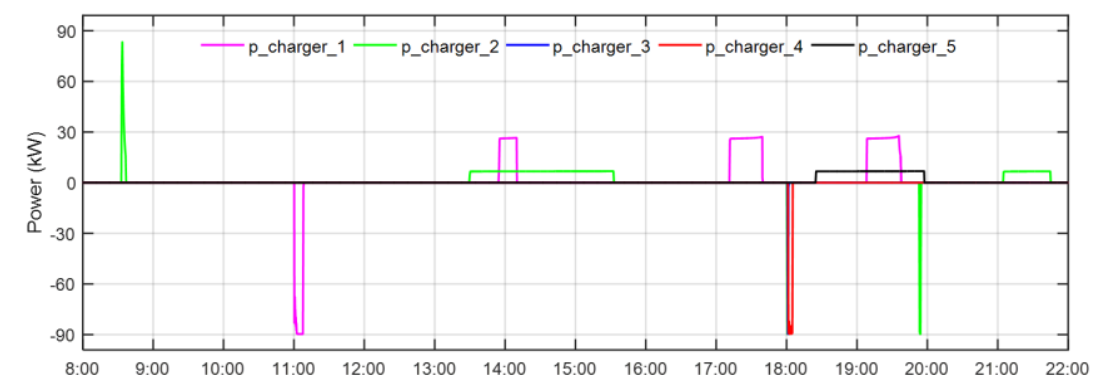

Figure 13. Power evolutions under ICDA. 


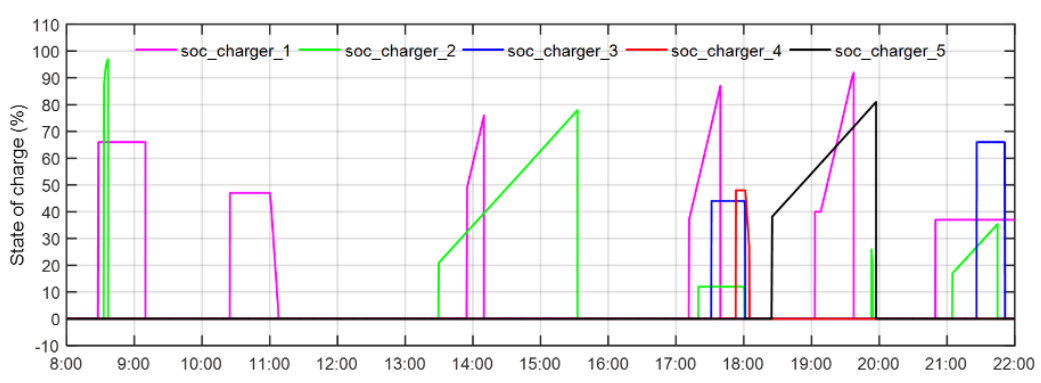

Figure 14. State of charge $\operatorname{soc}_{E V}$ evolutions under ICDA.

The operating time of EVs connected to charger 1 is shown in Figure 15. $t_{E V_{-} \text {charger_1 }}$ represents parking periods of EVs connected to charger 1. $t_{E V_{-} \text {operate }}$ represents the start operating time of EVs. $t_{E V_{-} \text {arrive }}$ represents the arrival time of EVs. $t_{E V_{-} \text {depart }}$ represents the departure time of EVs.

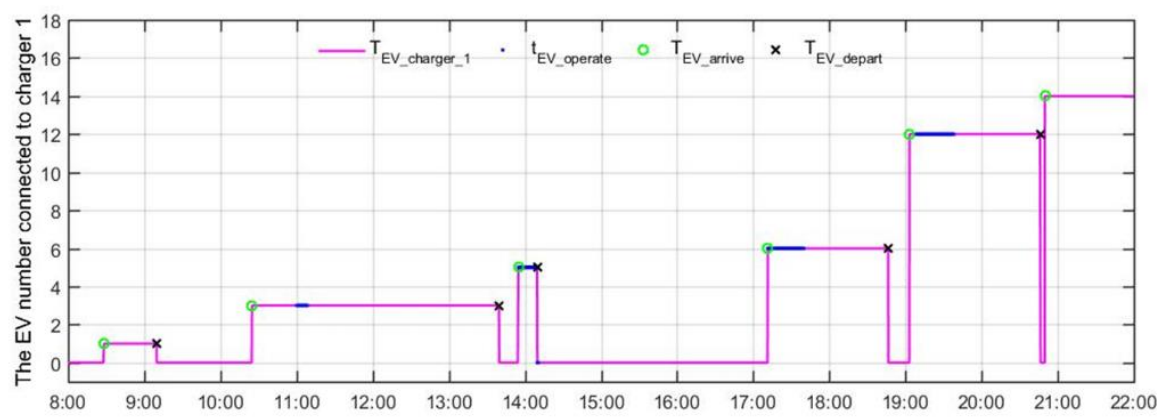

Figure 15. Operating time of EVs connected to charger 1 under ICDA.

As shown in Figure 15, EVs connected to the charger 1 in chronological order are the 1st, 3rd, 5th, 6th, 12th, 14th. After an EV arrives at the charging station, when the power is met, the charging/discharging operation begins. EVs that immediately start charging/discharging operations after arriving at the charging station are the 5th, 6th, 12th, while the 3rd EV enters the waiting state after arriving at the charging station, then discharges when power is met. Moreover, the 1st and 14th did not discharge until they left because of unsatisfactory power.

The operating time of EVs connected to charger 2 is shown in Figure 16. As shown in Figure 16, EVs connected to the charger 2 in chronological order are 2nd, 4th, 7th, 13th, 15th. EVs that immediately start charging/discharging operations after arriving at the charging station are the 2nd, the 4th, the 13th, the 15th EVs, while the 7th EV enters the waiting state after arriving at the charging station, then discharges when power is met.

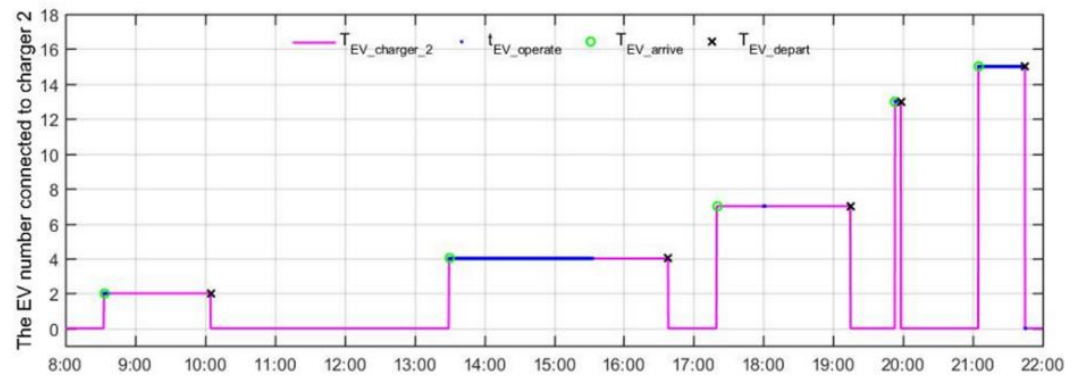

Figure 16. The operating time of EVs connected to charger 2 under ICDA.

The operating time of EVs connected to charger 3 is shown in Figure 17. As shown in Figure 17, EVs connected to the charger 3 in chronological order are the 8th and the 16th EVs. The 8th EV enters 
the waiting state after arriving at the charging station, then discharges when power is met, while the 16th EV did not charge until it left because of unsatisfactory power.

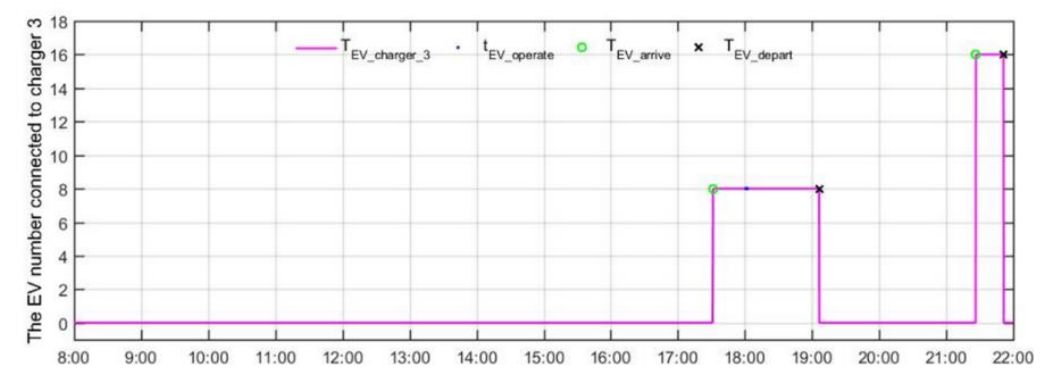

Figure 17. The operating time of EVs connected to charger 3 under ICDA.

The operating time of EVs connected to charger 4 is shown in Figure 18. As shown in Figure 18, the EV connected to charger 4 is the 9th EV. The 9th EV enters the waiting state after arriving at the charging station, then discharges when the power is met.

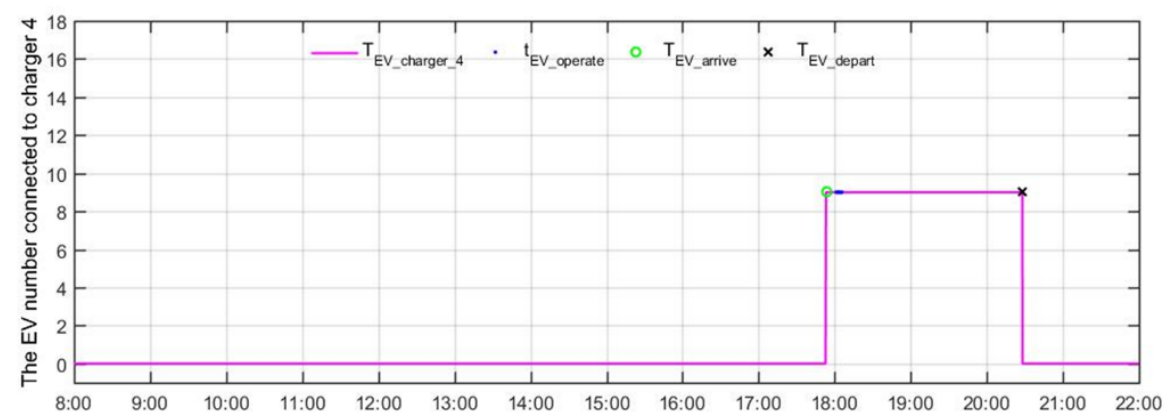

Figure 18. The operating time of EVs connected to charger 4 under ICDA.

The operating time of EVs connected to charger 5 is shown in Figure 19. The EV connected to the charger 5 is the 10th EV, which immediately starts charging/discharging operations after arriving at the charging station.

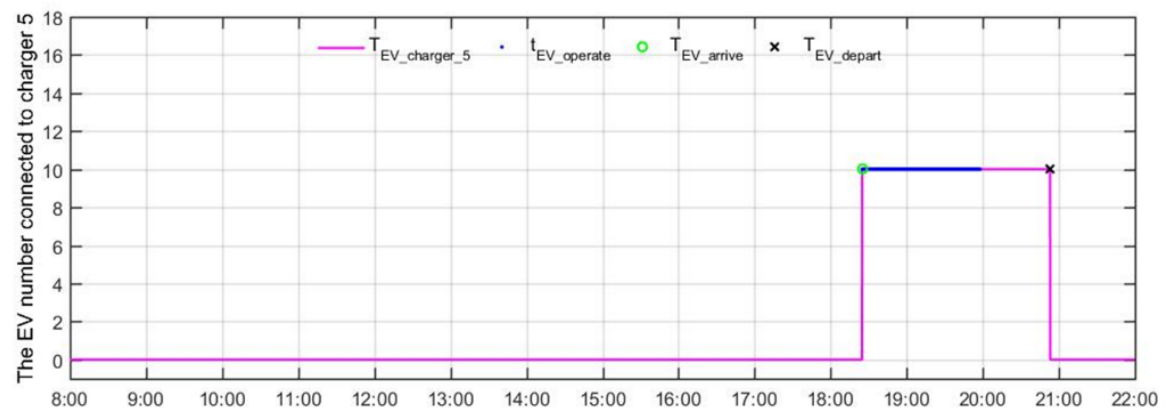

Figure 19. The operating time of EVs connected to charger 5 under ICDA.

The recording of EV charging under ICDA is shown in Figure 20. 


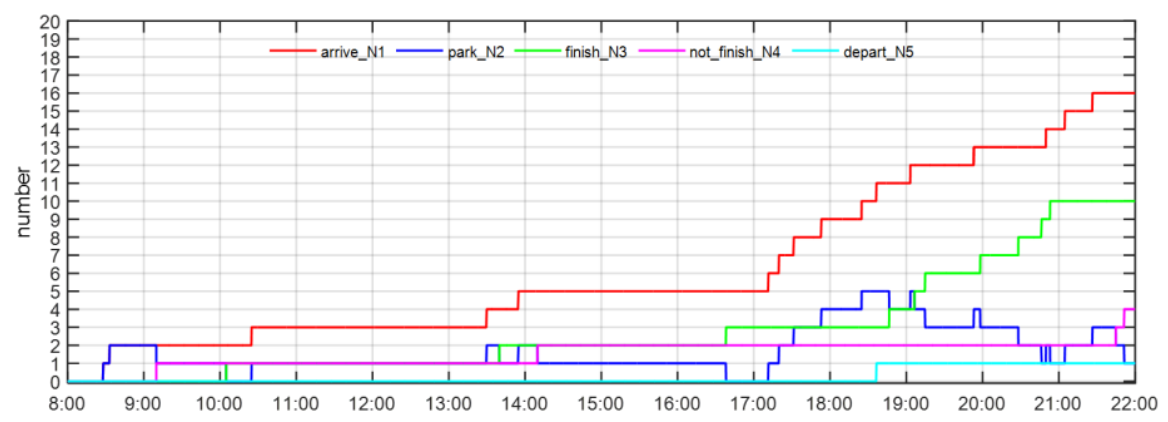

Figure 20. Recording of EV charging under ICDA.

The ratings arrive_N1, park_N2, finish_N3, not_finish_N4, and depart_N5 are, respectively, the number of EVs arrived at the charging station, the number of EVs parking at the charging station, the number of EVs that have completed operations, the number that has not completed operations, and the number of EVs leaving directly. The rating arrive_N1 is expressed by Equation (4):

$$
\text { arrive_N1 }=\text { park_N2 }+ \text { finish_N3 }+ \text { not_finish_N4 + depart_N5 }
$$

\subsection{Simulation Results under SPVA}

The second simulation works under SPVA and the EV cannot be charged/discharged until the estimated optimal start operating time of EVs is given by searching the "peak" periods and "valley" periods of the public grid; $t_{E V \_b e s t \_s}$ represents the optimal start operating time, and $t_{E V \_l a t e s t \_s t}$ represents the estimated latest operating time.

As shown in Figure 21, the steady DC bus voltage is $400 \mathrm{~V}$ within the simulation period, which proves that the power management strategy works well to balance the powers under SPVA.

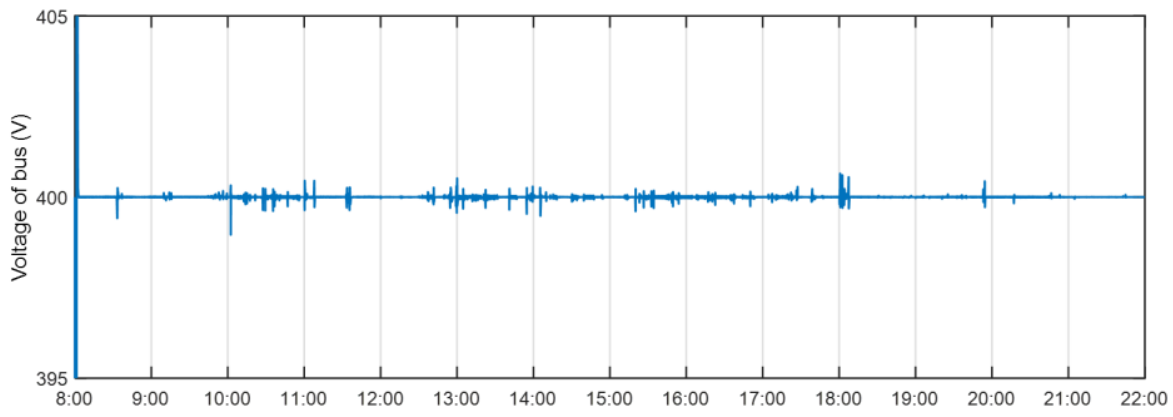

Figure 21. DC bus voltage evolution under SPVA.

Figure 22 shows the storage soc and distribution coefficient $k$ under SPVA. The evolutions of the state of charge soc and distribution coefficient $k$ show the feasibility of SPVA and respect the power flow given in Figure 2.

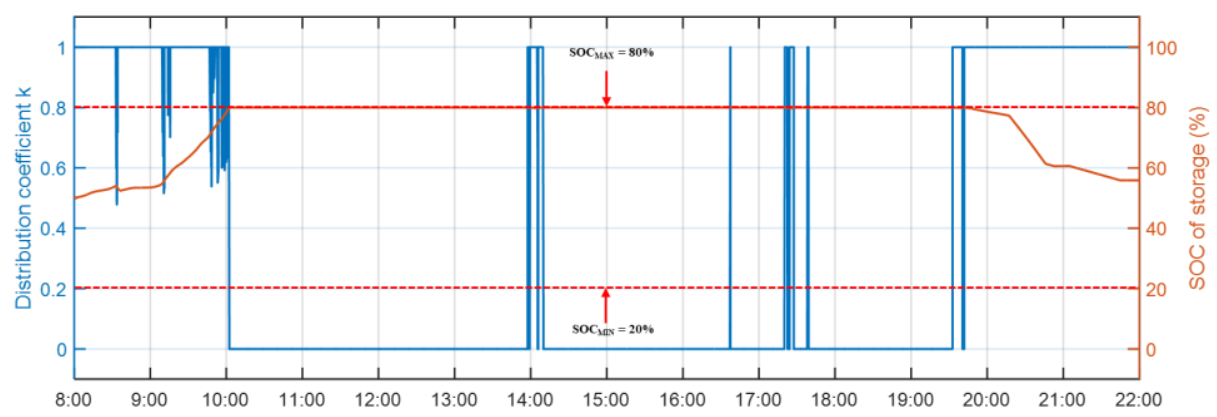

Figure 22. Storage soc and distribution coefficient $k$ under SPVA. 
Storage current evolution under SPVA is shown in Figure 23. As already mentioned, the absolute value of the storage current is limited to $115 \mathrm{~A}$, and the simulation result shows that the current is successfully limited.

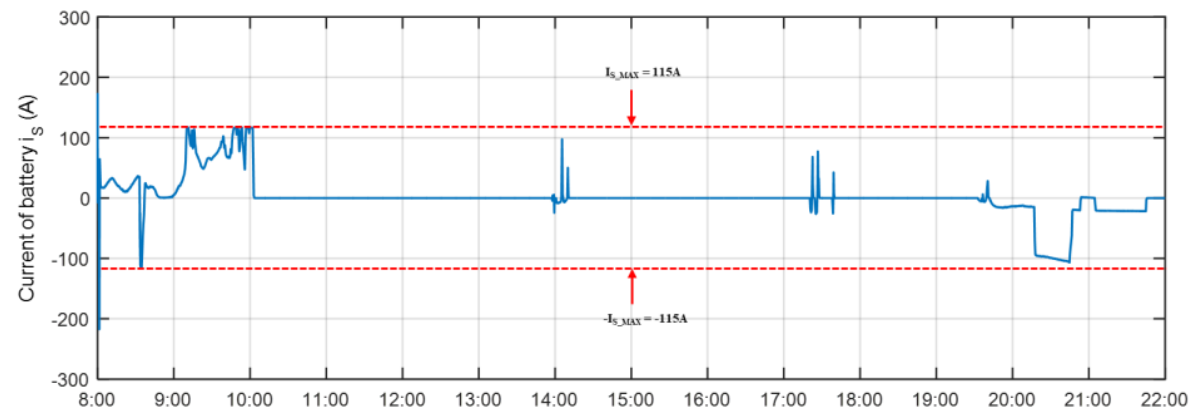

Figure 23. Storage current evolution under SPVA.

The power flow of DC microgrid under SPVA is shown in Figure 24. The grid power is within the imposed power limits during the simulation period, respecting the power flow given in Figure 2. Setting different power limits of the public grid in the "valley" period and the "peak" period provides a guarantee for the stability of the public grid.

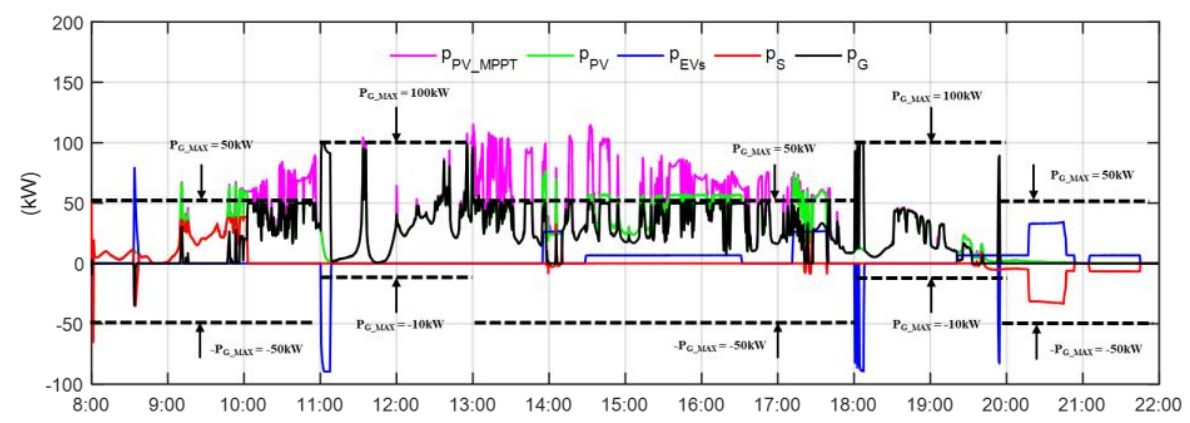

Figure 24. Power flow of DC microgrid under SPVA.

Figure 25 shows the parking periods of EVs. In order to compare the two algorithms, all the information about EVs in case one and case two are the same.

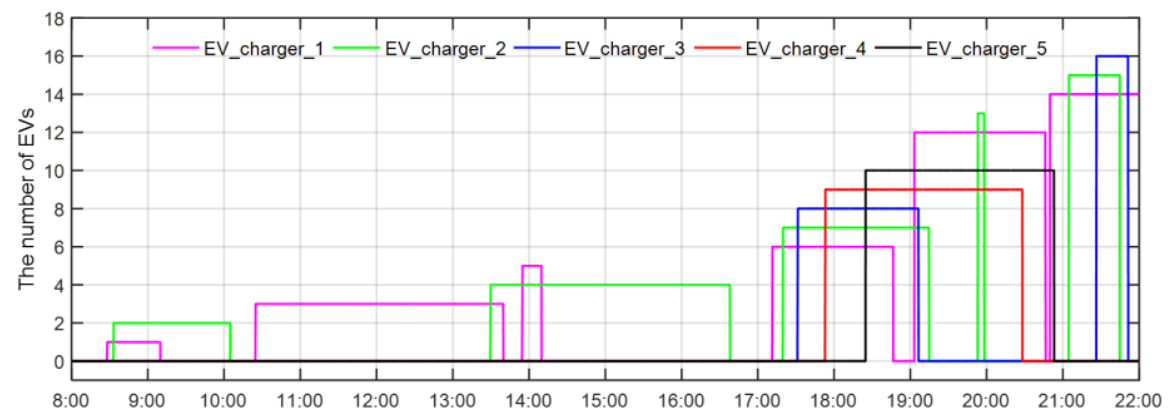

Figure 25. Parking periods of EVs at each charger.

The theoretical optimal start operating time and latest start operating time of EVs are shown in Table 4, which can be calculated by the EV charging station based on $T_{\text {arrive, }}, T_{\text {depart }}, S O C_{E V \_i n}$, $S O C_{E V_{-} \text {final_lim, }}$ charging modes, and discharge power. 
Table 4. Theoretical optimal start operating time and latest start operating time of EVs.

\begin{tabular}{|c|c|c|c|c|c|c|c|c|}
\hline Ordinal $_{E V}$ & 1st & 2nd & 3 rd & 4th & 5 th & 6th & 7 th & 8th \\
\hline$t_{E V \_b e s t \_s t}(100 \mathrm{~s})$ & 36.69 & 20.00 & 108.00 & 233.15 & 213.00 & 331.00 & 360.01 & 360.01 \\
\hline$t_{E V \_l a t e s t \_s t}(100 s)$ & 36.70 & 72.83 & 199.56 & 237.28 & 213.00 & 371.33 & 404.71 & 399.61 \\
\hline Ordinal $_{E V}$ & 9th & 10th & 11th & 12th & 13th & 14th & 15th & 16th \\
\hline$t_{E V \_b e s t \_s t}(100 s)$ & 360.01 & 408.56 & 382.00 & 442.40 & 428.00 & 462.00 & 471.00 & 497.42 \\
\hline$t_{E V \_l a t e s t \_s t}(100 \mathrm{~s})$ & 446.88 & 408.56 & 421.99 & 442.41 & 430.33 & 600.04 & 471.00 & 497.43 \\
\hline
\end{tabular}

The power evolutions under SPVA are shown in Figure 26. Compared with Figure 13, the 4th and the10th EVs are farther away from the "peak" periods of the public grid, while the 12th EV directly avoids the "peak" periods of the public grid, thereby preventing the public grid from overloading, meanwhile reducing charging costs, which proves the effectiveness and superiority of SPVA. Figure 27 shows the $\operatorname{soc}_{E V}$ evolutions under SPVA.

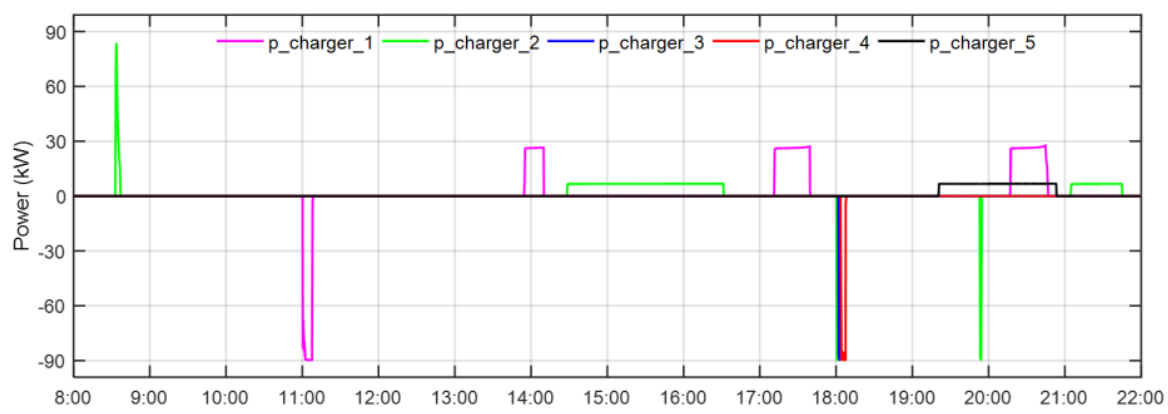

Figure 26. Power evolutions under SPVA.

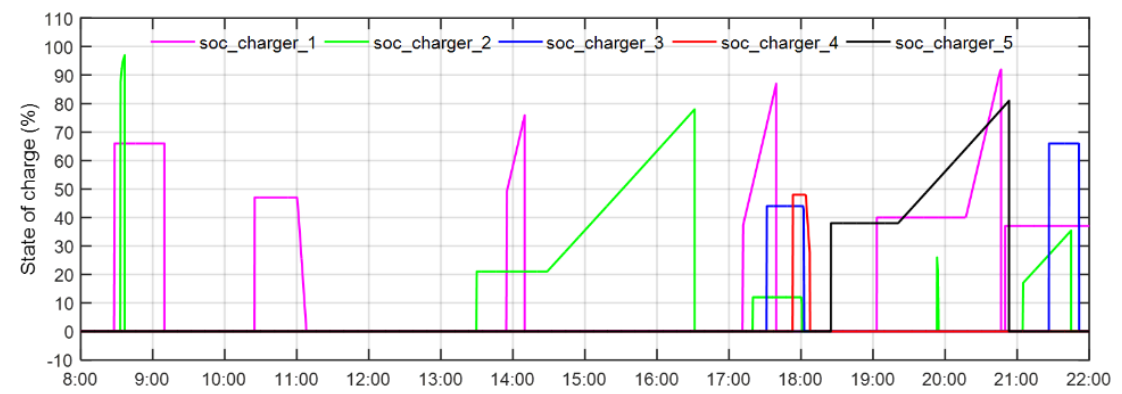

Figure 27. State of charge $\operatorname{soc}_{E V}$ evolutions under SPVA.

The operating time of EVs connected to charger 1 is shown in Figure 28. Compared with Figure 15, due to SPVA, the 12th EV did not choose to be charged immediately after arrival but waited for the optimal start operating time, which saved the user's charging costs and avoided adding peak loads to the public grid.

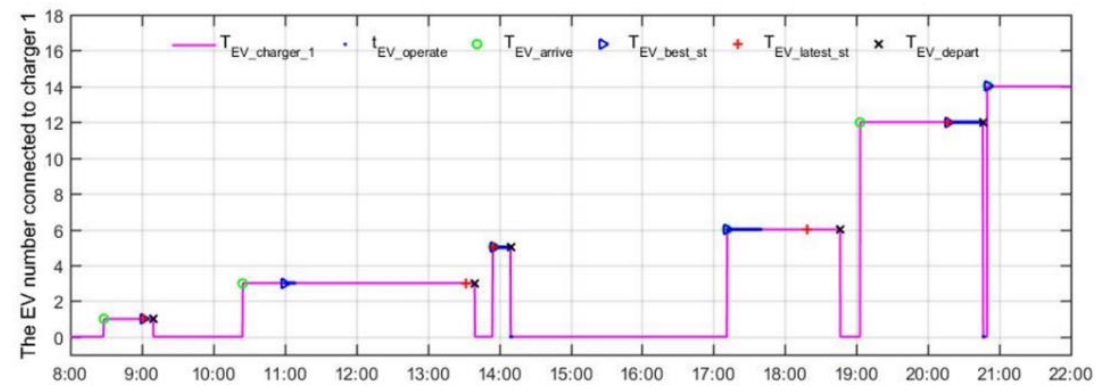

Figure 28. Operating time of EVs connected to charger 1 under SPVA. 
The operating time of EVs connected to charger 2 is shown in Figure 29. Compared with Figure 16, due to SPVA, the 4th EV did not choose to be charged immediately after arrival but waited for the optimal start operating time.

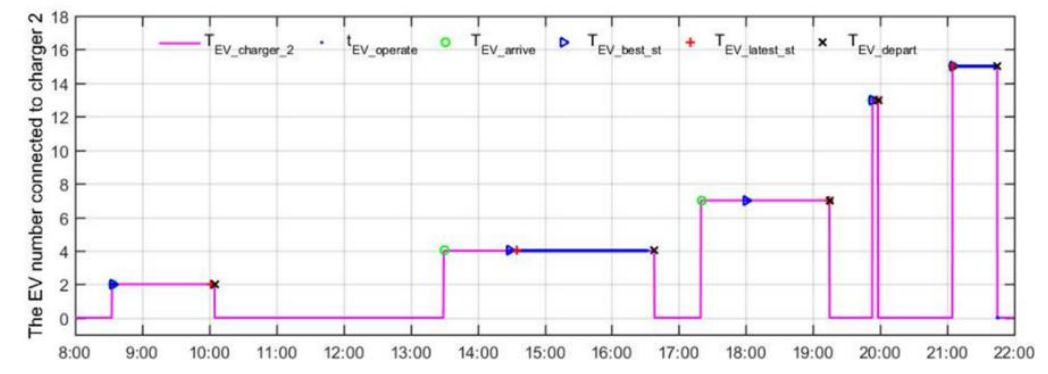

Figure 29. Operating time of EVs connected to charger 2 under SPVA.

The operating time of EVs connected to charger 3 is shown in Figure 30, and the 8th and the 16th EVs have the same operation results as Figure 17.

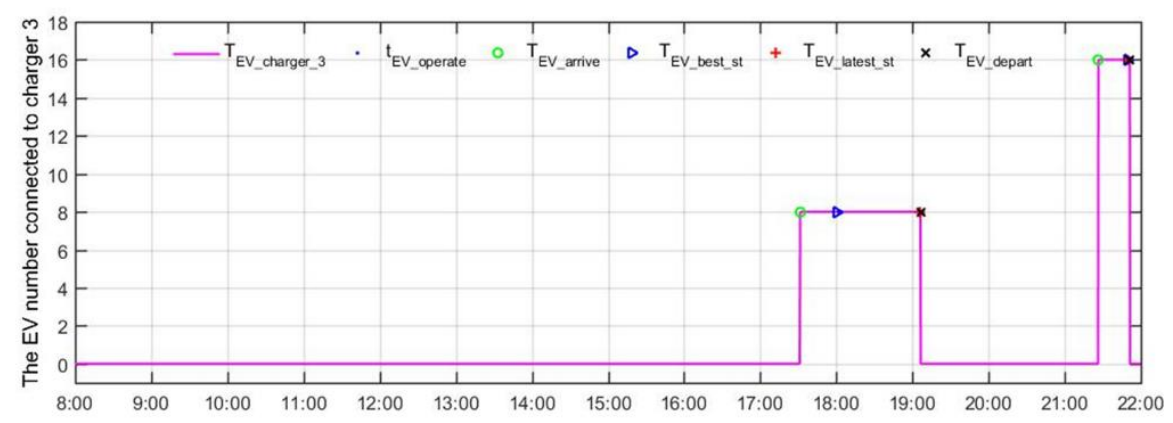

Figure 30. Operating time of EVs connected to charger 3 under SPVA.

The operating time of EVs connected to charger 4 is shown in Figure 31. The operating time of EVs connected to charger 5 is shown in Figure 32 and the 9th EV has the same operation result as Figure 18. Compared with Figure 19, due to SPVA, the 10th EV did not choose to be charged immediately after arrival but waited for the optimal start operating time.

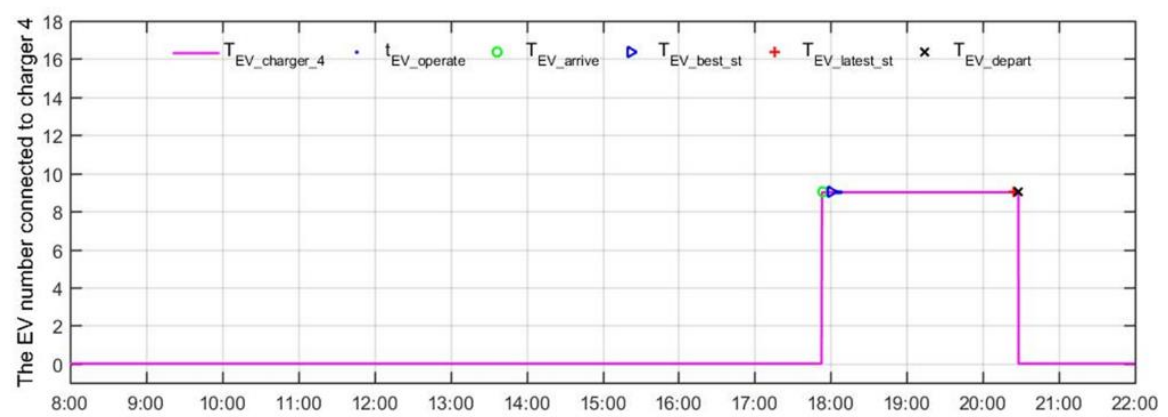

Figure 31. Operating time of EVs connected to charger 4 under SPVA. 


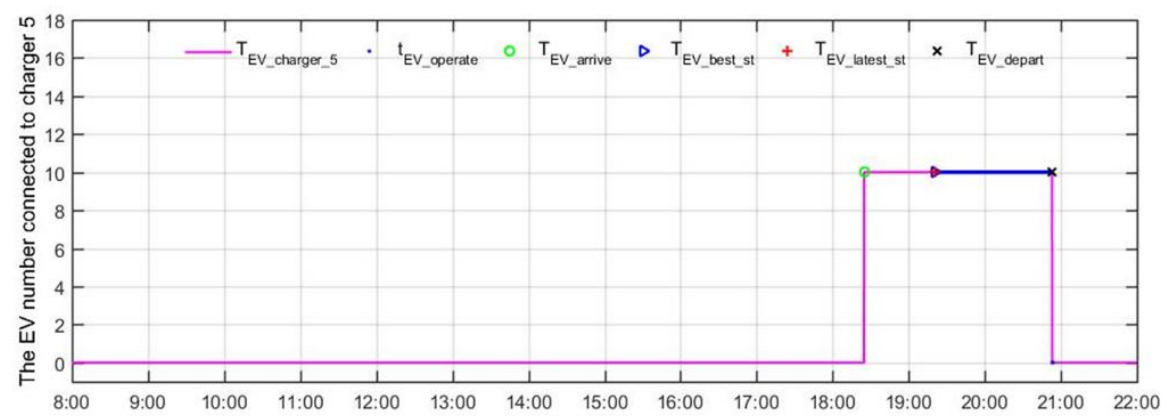

Figure 32. Operating time of EVs connected to charger 5 under SPVA.

The recording of EV charging under SPVA is shown in Figure 33, which respects Equation (4).

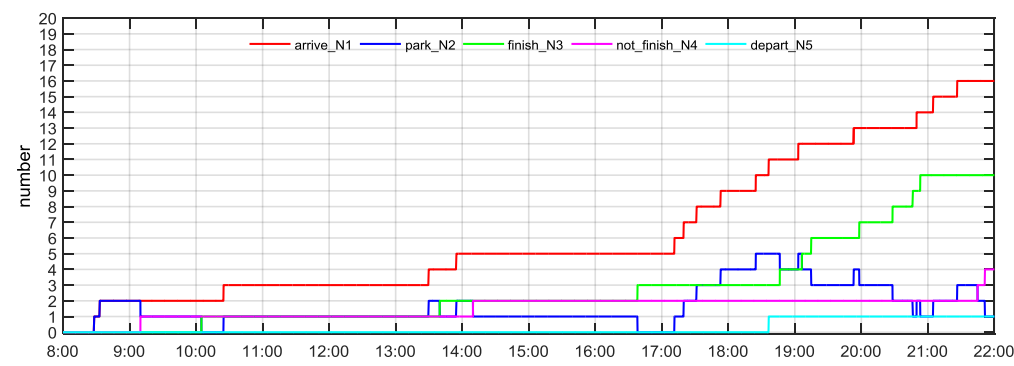

Figure 33. Recording of EV charging under SPVA.

\subsection{Comparison and Analysis of the Two Simulation Cases}

The simulation results of ICDA and SPVA are shown in Table 5, where $D_{c p}$ represents the completion degree of EVs, calculated by Equation (5):

$$
D_{c p}=\left|\frac{S O C_{E V_{-} \text {final }}-S O C_{E V \_ \text {in }}}{S O C_{E V_{-}} E V_{-i n f i n a l \_l i m}} \|\right|
$$

Table 5. Simulation results of ICDA and SPVA.

\begin{tabular}{ccccccccc}
\hline Ordinal $_{\boldsymbol{E V}}$ & $\mathbf{1 s t}$ & 2nd & 3rd & 4th & 5th & 6th & 7th & 8th \\
\hline Type $(1)$ & $\mathrm{DCH}$ & $\mathrm{CH}$ & $\mathrm{DCH}$ & $\mathrm{CH}$ & $\mathrm{CH}$ & $\mathrm{CH}$ & $\mathrm{DCH}$ & $\mathrm{DCH}$ \\
$D_{c p}(1)$ & $0 \%$ & $100 \%$ & $100 \%$ & $100 \%$ & $81.65 \%$ & $100 \%$ & $100 \%$ & $100 \%$ \\
Type $(2)$ & $\mathrm{DCH}$ & $\mathrm{CH}$ & $\mathrm{DCH}$ & $\mathrm{CH}$ & $\mathrm{CH}$ & $\mathrm{CH}$ & $\mathrm{DCH}$ & $\mathrm{DCH}$ \\
$D_{c p}(2)$ & $0 \%$ & $100 \%$ & $100 \%$ & $100 \%$ & $81.65 \%$ & $100 \%$ & $100 \%$ & $100 \%$ \\
\hline Ordinal $_{\boldsymbol{E V}}$ & $\mathbf{9 t h}$ & $\mathbf{1 0 t h}$ & $\mathbf{1 1 t h}$ & $\mathbf{1 2 t h}$ & $\mathbf{1 3 t h}$ & $\mathbf{1 4 t h}$ & $\mathbf{1 5 t h}$ & $\mathbf{1 6 t h}$ \\
\hline Type $(1)$ & $\mathrm{DCH}$ & $\mathrm{CH}$ & $\mathrm{CH}$ & $\mathrm{CH}$ & $\mathrm{DCH}$ & $\mathrm{DCH}$ & $\mathrm{CH}$ & $\mathrm{CH}$ \\
$D_{c p}(1)$ & $100 \%$ & $100 \%$ & $0 \%$ & $100 \%$ & $100 \%$ & $0 \%$ & $38.33 \%$ & $0 \%$ \\
Type $(2)$ & $\mathrm{DCH}$ & $\mathrm{CH}$ & $\mathrm{CH}$ & $\mathrm{CH}$ & $\mathrm{DCH}$ & $\mathrm{DCH}$ & $\mathrm{CH}$ & $\mathrm{CH}$ \\
$D_{c p}(2)$ & $100 \%$ & $100 \%$ & $0 \%$ & $100 \%$ & $100 \%$ & $0 \%$ & $38.33 \%$ & $0 \%$ \\
\hline
\end{tabular}

The parameter $\operatorname{soc}_{E V_{-}}$final represents the $\operatorname{soc}_{E V}$ when EVs leave the charging station. $D_{c p}(1)$ and $D_{c p}(2)$ are the completion degree of EVs under ICDA and SPVA, respectively.

Under the two algorithms, the completion degree of EVs is the same under ICDA and SPVA, as shown in Tables 5 and 6. 
Table 6. Results comparison of ICDA and SPVA.

\begin{tabular}{ccc}
\hline Algorithms & ICDA & SPVA \\
\hline EV number & 16 & 16 \\
Number of finishing CH or DCH & 11 & 11 \\
Energy cost of public grid power $(c €)$ & -280.4216 & -294.1568 \\
\hline
\end{tabular}

There are $11 \mathrm{EV}$ s with a completion degree of $100 \%$, while the 1st, 11th, 14th, and 16th EV have a completion degree of $0 \%$, among which, the 11th EV directly left after arriving at the charging station because the charging station could not meet the user need. The 5th EV has a completion degree of $81.65 \%$, and the 15 th EV with a completion degree of $38.33 \%$.

The comparison between the two algorithms highlights that the energy cost of public grid under ICDA is higher than that under SPVA. Thus, the power management strategy can run well under SPVA, ease the pressure on the public grid at the "peak" periods, and reduce the energy cost of the public grid.

\section{Conclusions}

This paper presents a power management strategy with integrated V2G to reduce the peak pressure of the public grid while meeting the needs of users. In the strategy, PV sources, battery storage, and the public grid are used to charge EVs in sequence; at the "peak" periods of the public grid, PV sources and EVs are discharged to the public grid one after another to play the role of V2G. The SPVA is proposed to judge the optimal charging/discharging start time of EVs, through its arrival time, departure time, $S O C_{E V_{-} i n}$, and $S O C_{E V_{-} \text {final_lim }}$, to achieve peak shaving and valley filling while reducing the cost of the public grid. In addition, in order to better maintain the stability of the public grid, the "peak" periods and "valley" periods of the public grid correspond to different power limits. Simulation results show that the charging station, based on a DC microgrid, can operate well considering the EV charging/discharging behaviors; the proposed SPVA is highly effective in reducing the cost of the public grid by calculating the optimal start operating time of EVs, while ensuring the stability of the public grid. The limitation of SPVA is that it does not consider the operating cost of the EV charging station. In the future, we can take into account the power prediction and load prediction through global optimization to minimize the operating cost of the EV charging station.

With the popularity of EVs, there will be certain rules for EVs arriving at the charging station every day, thus, the EV prediction system will be designed which can predict the current situation of EVs based on the EV data of the past few days. In addition, PV data can be predicted based on the weather forecast. With these two predictions, EV charging stations will have predictions about the usage of the public grid and batteries, which can better control the system and improve the stability of the system, laying a solid foundation for the production of fully intelligent EV charging stations in the future.

Author Contributions: Conceptualization, D.W., M.S., and F.L.; methodology, D.W., M.S., and F.L.; software, D.W.; validation, D.W.; formal analysis, D.W., M.S., and F.L.; investigation, D.W., M.S., and F.L.; resources, D.W., M.S., and F.L.; writing — original draft preparation, D.W.; writing—review and editing, M.S.; supervision, M.S., and F.L.; project administration, M.S.; funding acquisition, M.S. All authors have read and agreed to the published version of the manuscript.

Funding: This research was funded by ADEME France in the context of the call for projects APRED 2017, project MOBEL_CITY grant number \#1766C0006.

Conflicts of Interest: The authors declare no conflict of interest. 


\section{Abbreviations}

DC

EV

EVs

ICDA

G2V

PV

SPVA

STC

V2G

Nomenclature

$c_{P V}$

$c_{E V}$

$c_{P V}$

$C_{E R F}$

$D_{c p}$

$D_{c p}(1)$

$D_{c p}(2)$

$E_{\text {discharge }}$

Echgrge

$I_{S \_M A X}$

$J_{E V_{-} E R F}$

$k$

Ordinal $_{E V}$

$p_{\text {inject_G }}$

$P_{P V_{-} S T C}$

$p_{P V}$

$p_{E V s}$

$p_{E V \_t o t a l}$

$P_{\text {FAST_MAX }}$

$P_{\text {AVER_MAX }}$

$P_{\text {SLOW_MAX }}$

$P_{D I S}$

Soc $_{E V}$

$S O C_{M I N}$

$S_{S O C_{M A X}}$

$S O C_{E V_{-} \text {in }}$

$S O C_{E V_{-} \text {final_lim }}$

$t_{E V_{-} \text {charger_1 }}$

$t_{E V \_o p e r a t e}$

$t_{E V \_a r r i v e}$

$t_{E V \_ \text {depart }}$

$t_{E V \_b e s t \_s t}$

$t_{E V \_l a t e s t \_s t}$

$T_{\text {arrive }}$

$T_{\text {depart }}$

$v_{C_{-} R E F}$

\section{Direct Current}

Electric Vehicle

Electric Vehicles

Immediate Charge/Discharge Algorithm

Grid-to-Vehicle

Photovoltaic

Searching Peak and Valley Algorithm

Standard Test Conditions

Vehicle-to-Grid

The coefficient of PV power

The coefficient of the energy that EVs can release

The coefficient of PV power

The capacity of the storage (Ah)

The completion degree of EVs

The completion degree of EVs under ICDA

The completion degree of EVs under SPVA

The maximum energy that EVs can discharge $(\mathrm{kW})$

The maximum energy that EVs can be charged $(\mathrm{kW})$

The storage current limitation (A)

The battery energy of EV (kWh)

Distribution coefficient

The ordinal number of EVs

The power injected into the public grid $(\mathrm{kW})$

The estimated PV power under standard test conditions $(\mathrm{kW})$

$\mathrm{PV}$ power $(\mathrm{kW})$

Total power of EVs $(\mathrm{kW})$

The power that EVs can output $(\mathrm{kW})$

Maximal charging power demanded by fast mode $(\mathrm{kW})$

Maximal charging power demanded by average mode $(\mathrm{kW})$

Maximal charging power demanded by slow mode $(\mathrm{kW})$

The constant discharge power $(\mathrm{kW})$

State of charge

The soc lower limit

The soc upper limit

Initial state of charge

The state of charge limit at the time of departure

Parking periods of EVs connected to charger 1(s)

The start operating time of EVs (s)

The arrival time of EVs (s)

The departure time of EVs (s)

The optimal start operating time (s)

The estimated latest operating time (s)

The time each EV arrives at the charging station (s)

The time each EV leaves the charging station (s)

The rated voltage of DC bus (V)

\section{References}

1. IEA. Global EV Outlook 2019; IEA: Paris, France, 2019. Available online: https://www.iea.org/reports/globalev-outlook-2019 (accessed on 7 December 2019). 
2. Wang, Z.; Zhang, Y.; You, S.; Xiao, H.; Cheng, M. An Integrated Power Conversion System for Electric Traction and V2G Operation in Electric Vehicles with a Small Film Capacitor. IEEE Trans. Power Electron. 2020, 35, 5066-5077. [CrossRef]

3. Gjelaj, M.; Hashemi, S.; Andersen, P.B.; Traeholt, C. Optimal infrastructure planning for EV fast-charging stations based on prediction of user behaviour. IET Electr. Syst. Transp. 2020, 10, 1-12. [CrossRef]

4. Wang, S.; Dong, Z.Y.; Chen, C.; Fan, H.; Luo, F. Expansion Planning of Active Distribution Networks with Multiple Distributed Energy Resources and EV Sharing System. IEEE Trans. Smart Grid 2020, 11, 602-611. [CrossRef]

5. Dai, S.; Gao, F.; Guan, X.; Yan, C.; Liu, K.; Dong, J.; Yang, L. Robust Energy Management for a Corporate Energy System with Shift-Working V2G. IEEE Trans. Autom. Sci. Eng. 2020, 1-18. [CrossRef]

6. Wang, Q.L.; Liu, X.; Du, J.; Kong, F.X. Smart Charging for Electric Vehicles: A Survey from the Algorithmic Perspective. IEEE Commun. Surv. Tutor. 2016, 18, 1500-1517. [CrossRef]

7. Xia, Y.; Hu, B.; Xie, K.; Tang, J.; Tai, H. An EV Charging Demand Model for the Distribution System Using Traffic Property. IEEE Access 2019, 7, 28089-28099. [CrossRef]

8. Habib, S.; Khan, M.M.; Abbas, F.; Sang, L.; Shahid, M.U.; Tang, H. A Comprehensive Study of Implemented International Standards, Technical Challenges, Impacts and Prospects for Electric Vehicles. IEEE Access 2018, 6, 13866-13890. [CrossRef]

9. Chekired, D.A.; Khoukhi, L.; Mouftah, H.T. Decentralized Cloud-SDN Architecture in Smart Grid: A Dynamic Pricing Model. IEEE Trans. Ind. Inf. 2018, 14, 1220-1231. [CrossRef]

10. Hoang, D.T.; Wang, P.; Niyato, D.; Hossain, E. Charging and discharging of plug- in electric vehicles (PEVs) in vehicle-to-grid (V2G) systems: A cyber insurance-based model. IEEE Access 2017, 5, 732-754. [CrossRef]

11. Lee, B.; Kim, J.; Kim, S.; Lee, J. An Isolated/Bidirectional PWM Resonant Converter for V2G(H) EV On-Board Charger. IEEE Trans. Veh. Technol. 2017, 66, 7741-7750. [CrossRef]

12. Li, F.; Guo, L.; Liu, L.; Li, X.; Wang, Q. Method to improve charging power quality of electric vehicles. J. Eng. 2019, 2019, 2706-2709. [CrossRef]

13. Rahmani-Andebili, M. Vehicle-for-grid (VfG): A mobile energy storage in smart grid. IET Gener. Transmiss. Distrib. 2019, 13, 1358-1368. [CrossRef]

14. Shi, R.; Sun, C.; Zhou, Z.; Zhang, L.; Liang, Z. A robust economic dispatch of residential microgrid with wind power and electric vehicle integration. In Proceedings of the 2016 Chinese Control and Decision Conference (CCDC), Yinchuan, China, 28-30 May 2016.

15. Alam, M.J.E.; Muttaqi, K.M.; Sutanto, D. Effective utilization of available PEV battery capacity for mitigation of solar PV impact and grid support with integrated V2G functionality. IEEE Trans. Smart Grid 2016, 7, 1562-1571. [CrossRef]

16. Sovacool, B.K.; Noel, L.; Axsen, J.; Kempton, W. The neglected social dimensions to a vehicle-to-grid (V2G) transition: A critical and systematic review. Environ. Res. Lett. 2018, 13, 013001. [CrossRef]

17. Ravichandran, A.; Sirouspour, S.; Malysz, P.; Emadi, A. A Chance-Constraints-Based Control Strategy for Microgrids With Energy Storage and Integrated Electric Vehicles. IEEE Trans. Smart Grid 2018, 9, 346-359. [CrossRef]

18. Yang, Z.; Mehdi, N.; Tatari, O. Vehicle to grid regulation services of electric delivery trucks: Economic and environmental benefit analysis. Appl. Energy 2016, 170, 161-175.

19. Sechilariu, M. Intelligent Energy Management of Electrical Power Systems. Appl. Sci. 2020, 10, 2951. [CrossRef]

20. Locment, F.; Sechilariu, M. DC microgrid for future electric vehicle charging station designed by Energetic Macroscopic Representation and Maximum Control Structure. In Proceedings of the IEEE International Energy Conference (ENERGYCON), Cavtat, Croatia, 13-16 May 2014.

21. Sechilariu, M.; Locment, F.; Darene, N. Social Acceptance of Microgrids Dedicated to Electric Vehicle Charging Stations. In Proceedings of the IEEE International Conference on Renewable Energy Research and Applications (ICRERA), Paris, France, 14-17 October 2018.

22. Sechilariu, M.; Molines, N.; Richard, G. Electromobility Framework Study: Infrastructure and Urban Planning for EV Charging Station Empowered by PV-based Microgrid. IET Electr. Syst. Transp. 2019, 9, 176-185. [CrossRef]

23. Locment, F.; Sechilariu, M. Modeling and Simulation of DC Microgrids for Electric Vehicle Charging Stations. Energies 2015, 8, 4335-4356. [CrossRef]

24. Wang, S.N.; Yang, S.B. Optimal minimization of plug-in electric vehicle charging cost with vehicle-to-home and vehicle-to-grid concepts. IEEE Trans. Veh. Technol. 2018, 67, 10281-10292.

25. Zhou, T.; Sun, W. Research on multi-objective optimisation coordination for large-scale V2G. IET Renew. Power Gener. 2020, 14, 445-453. [CrossRef] 
26. Sarker, M.R.; Olsen, D.J.; Ortega-Vazquez, M.A. Co-Optimization of Distribution Transformer Aging and Energy Arbitrage Using Electric Vehicles. IEEE Trans. Smart Grid 2017, 8, 2712-2722. [CrossRef]

27. Shi, Y.; Tuan, H.D.; Savkin, A.V.; Duong, T.Q.; Poor, H.V. Model Predictive Control for Smart Grids with Multiple Electric-Vehicle Charging Stations. IEEE Trans. Smart Grid 2019, 10, 2127-2136. [CrossRef]

28. Aluisio, B.; Conserva, A.; Dicorato, M.; Forte, G.F.; Trovato, M. Optimal operation planning of V2G-equipped Microgrid in the presence of EV aggregator. Electr. Power Syst. Res. 2017, 152, 295-305. [CrossRef]

29. Ashique, R.H.; Salam, Z.; Aziz, M.J.B.A.; Bhatti, A.R. Integrated photovoltaic-grid dc fast charging system for electric vehicle: A review of the architecture and control. Renew. Sustain. Energy Rev. 2016, 69, 1243-1257. [CrossRef]

30. Sechilariu, M.; Locment, F. Urban DC Microgrid: Intelligent Control and Power Flow Optimization, 1st ed.; Butterworth-Heinemann: Oxford, UK, 2016; pp. 57-58.

31. Wang, D.; Locment, F.; Sechilariu, M. Modelling, Simulation, and Management Strategy of an Electric Vehicle Charging Station Based on a DC Microgrid. Appl. Sci. 2020, 10, 2053. [CrossRef]

32. Boglou, V.; Karavas, C.-S.; Arvanitis, K.; Karlis, A. A Fuzzy Energy Management Strategy for the Coordination of Electric Vehicle Charging in Low Voltage Distribution Grids. Energies 2020, 13, 3709. [CrossRef]

33. Marra, F.; Yang, G.Y.; Traholt, C.; Larsen, E.; Rasmussen, C.N.; You, S. Demand profile study of battery electric vehicle under different charging options. In Proceedings of the IEEE Power Energy and Energy Society General Meeting, San Diego, CA, USA, 22-26 July 2012.

34. Bai, W.; Sechilariu, M.; Locment, F. DC Microgrid System Modeling and Simulation Based on a Specific Algorithm for Grid-Connected and Islanded Modes with Real-Time Demand-Side Management Optimization. Appl. Sci. 2020, 10, 2544. [CrossRef]

(C) 2020 by the authors. Licensee MDPI, Basel, Switzerland. This article is an open access article distributed under the terms and conditions of the Creative Commons Attribution (CC BY) license (http://creativecommons.org/licenses/by/4.0/). 